\title{
Research on China 's Antimonopoly Review of "Acquiring a small number of non-controlling equity"
}

\author{
Zhengjia Fu and Ziqi Wang \\ Capital university of economics and business, Fengtai, Beijing, China \\ Capital university of economics and business, Fengtai, Beijing, China \\ 441586900@qq.com, 1354832581@qq.com
}

\section{Zhengjia Fu}

Keywords: a small number of non-controlling equity; anti-monopoly decisive influence; substantial influence; stock right acquisition

\begin{abstract}
Once the control power of the acquired party is not transferred in the process of acquisition of a listed company, there is no need to make declaration to the anti-monopoly law enforcement organs for approval, but even if the acquisition of a small number of non-controlling equity has already caused the effects of damage and restricted competitions to a certain extent. This paper will, by defining and analyzing a small number of non-controlling equity, further explores the hidden dangers existing in the acquisition of a small number of non-controlling equity, and combined with several cases as well as the provisions of foreign laws, and finally conclude the review methods and mechanism for the acquisition of a small number of non-controlling equity, thereby offering a little bit contributions to the perfection of the regulations of Anti-monopoly Law.
\end{abstract}

\section{Theoretic differentiation of a small number of non-controlling equity}

\subsection{Case background of theoretical research on a small number of non-controlling equity}

On August 1, 2016, Uber founder and CEO Travis Kalanick received attention due to an open letter in his micro-blog. Soon afterwards, Didi Taxi officially announced that it would reach a strategic agreement with Uber Global, and acquire China Uber's brand, business, data and other assets for operation in mainland China. As a result, Didi Taxi and Uber Global would, through mutual acquisition, hold a certain proportion of minority interest of the other party, and become one of the minority stockholders of each other, of which Uber Global will hold 5.89\% of Didi's stock rights.

On August 10, 2015, Suning Commerce Group announced that Alibaba would hold 19.9\% of its total equity of non-public offering and become the second largest shareholder of Suning Commerce Group, and besides, it would obtain two nominations of the board of directors in the future. In the above acquisition cases, the transfer of a small number of non-controlling equity has become the core focus of the whole process, while in the process of the acquisition of a small number of non-controlling equity, whether it is required to conduct a review of anti-monopoly remains the central issue of focus.

\subsection{Concept and analysis of a small number of non-controlling equity}

A small number of non-controlling equity, just as its name implies, refers to that is only in the minority in the total equity of a listed company, and does not exert a decisive influence on the controlling nature of the listed company. Such equity acquisition does not involve the circumstances that the state conducts an investigation and the company takes the initiative to make declaration; and from the perspective of the legislators, when the acquisition of listed companies is carried out, the acquiring company has acquired the minority interest of the acquired company, while the minority interest will not produce a controlling influence over the decision-making of the board of shareholders, which may further change major strategies of the original company and influence the 
the stockholders' equity ${ }^{1}$ of old shareholders and provide economic benefits for the acquirer in disguised form.

But even if casting aside the controlling influence over the company's major strategic decisions, the most subtle equity transfer is likely to be transformed into a decision-making capacity targeted at vertical downstream customers, or a competition pressure specific to horizontal competition objects. In this way, in the case that the control power is regulated, such an invisible "controlling influence" is intensively reflected in the acquisition of the company through the transformation of a small number of non-controlling equity.

\section{The impact of the acquisition of minority interests and the defects of "control power" "decisive influence" specified in Chinese laws}

\subsection{The influence on vertical downstream customers}

From a vertical point of view, the influence arising from the acquisition of a small number of non-controlling equity is more of a determining ability. No matter whether the minority interest has made the acquirer produce certain influence in the decision-making of the target company, from the capacity point of view, either party as the horizontal direct competitor will not easily raise prices before the acquisition because the price increase will push downstream customers to the other side ${ }^{2}$; while after the successful acquisition, since the target company is the direct competitor of the acquirer and the acquirer obtains some economic benefits of the target company by purchasing the "minority interest", the acquirer has the practical ability to gain higher profits by unilaterally limiting its own productivity or increasing the prices. Therefore, the party on the side of vertical downstream customers is facing that the mutually restricting enterprises in the past begin to work together for collusion, and on the basis that the premise of price increase can be surely achieved, its own economic interests will inevitably be affected to a large extent.

\subsection{The influence on horizontal competition subjects}

From a horizontal point of view, although it seems from the appearance that a small number of non-controlling equity does not have controlling nature, there will exist a relatively obvious pressure of competition as well. Take an obvious case for example. A Company has controlled $1 / 2$ shares of the whole market while B Company and C Company have controlled $1 / 4$ shares of it, then if A Company only acquires $10 \%$ equity of B Company, from the aspect of appearance, $10 \%$ equity will not inevitably have the controlling power over the decision-making of B Company; but from the perspective of B Company, A and B have inevitably become a nominal interest community, and it means that $3 / 4$ shares of the whole market may be influenced or dominated by the same decision. It turns out that beyond the group of the acquirer and the acquired party, among other horizontal competitors, the original minority changes into the relative majority facing the competitive pressure, and even if the acquisition of a small number of equity exerts little impact, but the competition pressure arising therefrom will turn out to be quite obvious, and undoubtedly, the competitors as a third party are unwilling to see such a situation ${ }^{3}$.

\subsection{The defects of "control power" "decisive influence" specified in Chinese laws}

It is provided for in Article 3 of Guiding Opinions on the Centralized Declaration of Operators promulgated by Ministry of Commerce in 2014 that:

When judging whether the operators have obtained the control power over other operators through transactions or can exert decisive influence over other operators, it is usually required to

\footnotetext{
${ }^{1}$ A Brief Analysis of the Definition of Protection of Equities of Medium and Small Shareholders. Zhao Zhefeng.Fazhi Yu Jingji(The Last Ten-day Period).2013(10)

${ }^{2}$ Risk Aversion and System Improvement of Equity Transfer. Ye Kai. Market Weekly (Theoretical Research).2011(12)

${ }^{3}$ Regulation Dilemma and Countermeasures of the Concentration of Undertakings of the Minority Interest Behaviors in Enterprise Acquisition. Cheng Shang.Theory Monthly.2016(06)
} 
consider the following factors, including but not limited to: transaction purpose, equity structure, voting mechanism of the board of shareholders, etc. Although it puts forward the contents including but not limited to seven factors, it simply lists the factors, such an issue still remains an indistinct boundary on how to exert decisive influence and further produce the result of limiting competition while giving a comprehensive consideration of each factor, and detailed influencing effects fails to be presented in the form of legal articles, and it is still unable to meet the standards of conducting an anti-monopoly review of the minority interest.

\section{Analysis of EU M\&A cases and the review system perspective of a small number of non-controlling equity of $\mathbf{E} \mathbf{U}$}

\subsection{The case of Ryanair's acquisition of Aer Lingus under the investigation of EU}

In 2006, case of Ryanair's acquisition of Aer Lingus under the investigation of EU makes the EU aware of the regulation of a small number of non-controlling equity, and the specific case is as follows:Both the acquirer and the target company are Irish airlines, Ryanair intends to carry out a hostile acquisition of all equities of Aer Lingus, and as of November 13, 2006, Ryanair's acquisition of Aer Lingus is as high as $25.17 \%$. European Commission made a decision of prohibiting the transaction to the case on June 27, 2007, and during the investigation period of this case, the target company Aer Lingus proposed to European Commission that if European Commission finally made the decision of prohibiting the concentration of undertakings, given that the acquirer Ryanair has partially implemented the "concentration" that has been banned,.

Finally, after holding the minority interest of Aer Lingus, Ryanair can influence the combined strategy of Aer Lingus and other competitors, thereby unilaterally limiting Aer Lingus to compete with it, thus seriously reducing the competitions of the civil aviation market in the UK and Ireland. Therefore, Britain's Office of Fair Trading requested Ryanair to reduce the holdings of Aer Lingus' shares by $5 \%$ so as to finally solve the realistic problems of controlling power in the case, as well as the loopholes existing in EUMR on the provisions of control contents, and besides, make a presentation of the case and declare where it stands in terms of a more detailed division of the controlling nature in the white paper released in 2014 later.

\subsection{Contents of regulatory statutes formulated by EU over a small number of non-controlling equity}

In the course of settling the case, the European Commission recognized the urgency of regulating a small number of non-controlling equity, and on July 9, 2014, the European Commission proposed a number of solutions in the released white paper ${ }^{4}$ in terms of the acquisition of "minority interest", and the main purpose is to include the issue in the investigation scope of the European Commission. According to the regulation, if a transaction leads to a sustained change in the control power of the enterprise concerned, and then brings a sustained change to the market mechanism, then the behavior constitutes "concentration": first of all, a small number of equity acquisition enterprises and the target enterprise form the relationship of direct competition or the transaction relationship of the upstream and downstream markets. In the next place, the connection of competition is significant, that is, the share of acquisition equity has reached $20 \%$, or remains between $5 \%$ and $20 \%$, but there are other additional factors ${ }^{5}$. Again, additive factors include that the acquiring enterprise obtains the substantive veto power of the target enterprise, nomination right of the members of the board of directors of the target enterprise, as well as the right to obtain information relating to the key business decisions of the target enterprise, or the right to exert certain influence over the target enterprise.

\footnotetext{
${ }^{4}$ Towards more effective EU merger control

${ }^{5}$ A Fresh Look at the EU Merger Regulation? The European Commission's White Paper "Towards More Effective EU Merger Control" [J]. Ulrich von Koppenfels. Liverpool Law Review.2015-08-15
} 


\section{Suggestions on the anti-monopoly investigation of a small number of non-controlling equity in China}

\subsection{The core investigation standards of a small number of non-controlling equity in Anti-monopoly Law}

We should learn from the legal provisions of the EU and even the UK, integrate the two terms of "controlling nature" and "decisive influence" reasonably, and in details, we should refer to the legal provisions of the EU, and add the distinctions and proportions of investigation in the acquisition of the minority interest, as well as the specific contents in the market operation after the acquisition similar to the majority voting power. For instance, the one-vote veto of major strategic decisions of the acquired target company, the decision-making of business plans, the appointment of executives, more than half of the voting right of the budgetary approval authority, etc., and only these more specific examples of substantive influence will provide a good theoretical and legal basis for the work of the national anti-monopoly law enforcement organs better ${ }^{6}$.

\subsection{Improvement of the investigation mechanism for a small number of non-controlling equity}

It is able to effectively understand and solve the anti-monopoly investigation problems of the acquisition of a small number of non-controlling equity better only by expanding the investigation scope of a small number of non-controlling equity, and based on the legal basis in the previous text, granting the anti-monopoly investigation agencies a certain degree of power of examination and discretion, and in the specific law enforcement case of the anti-monopoly investigation, take the initiative to supervise more detailed controlling contents systematically in addition to reviewing the declaration materials of the acquiring company, and strengthening the training of special personnel.

\subsection{Perfect the declaration and burden of proof system of a small number of non-controlling equity}

Additionally set the report channel of the monopoly of a small number of non-controlling equity, not merely stipulate the declaration system in the original legal articles, and the establishment of the reporting system of the external third party has played a fairly good role in finding and controlling the monopoly of the minority interest ${ }^{7}$. Therefore, reverse the burden of proof, and the acquirer and the acquired target company themselves provide the evidence to prove the non-existence of decisive influence, and in this way, it is possible to effectively solve the monopoly investigation problem of a small number of non-controlling equity to a legal and and reasonable extent.

\section{References:}

[1] Cheng Shang. Regulation Dilemma and Countermeasures of the Concentration of Undertakings of the Minority Interest Behaviors in Enterprise Acquisition [J].Theory Monthly, 2016.

[2] Wang Weimin. A Brief Analysis of Risk Control of Equity Transactions [J].Legal System and Society, 2010.

[3] Ye Kai. Risk Aversion and System Improvement of Equity Transfer [J].Market Weekly(Theoretical Research), 2011.

[4] Zhao Zhefeng. A Brief Analysis of the Definition of Protection of Equities of Medium and Small Shareholders [J]. Fazhi Yu Jingji (The Last Ten-day Period), 2013.

\footnotetext{
${ }^{6}$ Research on the Legal Definition Model of the Concentration of Undertakings.Ye Jun.China Legal Science.2015(10)

${ }^{7}$ Comparative Study on the Negotiation System Before the Declaration of the Concentration of Undertakings.Zhang

Dong. Study of Comparative Law.2013(09)
} 